\title{
Preventive and therapeutic effect of Corn Cervi Pantotrichum on bone tissue in ovariectomized rats through activation of BMP-2/Smads/Runx2 signal transduction pathway.
}

\author{
Wei Gong1, Hongxin Zheng ${ }^{2 *}$, Feng $\mathrm{Li}^{2 *}$, Leiming Qu ${ }^{1}$, Wei Liu ${ }^{2}$ \\ ${ }^{1}$ Affiliated Hospital of Liaoning University of Traditional Chinese Medicine, Liaoning, PR China \\ ${ }^{2}$ Liaoning University of Traditional Chinese Medicine, Liaoning, PR China
}

\begin{abstract}
Objective: Corn Cervi Pantotrichum, a traditional Chinese medicine, has been used to treat postmenopausal osteoporosis for a long time, but the mechanism is not clear. This study aimed to examine in detail the effects of Corn Cervi Pantotrichum on the bone of postmenopausal osteoporosisrat model.

Materials and methods: forty female rats were randomly divided into groups of: Sham operated (Sham), ovariectomized control, ovariectomized with Corn Cervi Pantotrichum and ovariectomized with ERT (Climen). The Corn Cervi Pantotrichum and ERT were administered through the route of oral gavage daily at the dose of 0.4 g.kg-1 and $0.2 \mathrm{mg} . \mathrm{kg}^{-1}$ respectively. Following 12 weeks of treatment, rats were anesthetized. The blood and the distal of left femur were for bone biomarker using Elisa. The right femur was measured for BMD (bone mineral density) and histopathological evaluation. The head of left femur were used for quantitative real-time PCR and Western blot.

Results: Compared to the OVX group, supplementation of Corn Cervi Pantotrichum could not only increase the BMD of femur, but also increase the expression of bone formation maker. Photomicrograph of femur showed that Corn Cervi Pantotrichum can restore the normal architecture. Both Elisa, the quantitative real-time PCR and the Western blot results showed that Corn Cervi Pantotrichum may upregulates BMP-2/Smad1, 5/Runx2 expression in OVX rats.

Conclusion: This confirmed that Corn Cervi Pantotrichum could be used for the prevention of postmenopausal osteoporosis.
\end{abstract}

Keywords: Corn Cervi Pantotrichum, Menopause, Osteoporosis, BMP-2/Smad1, 5/Runx2 signal transduction pathway. Accepted on May 16, 2018

\section{Introduction}

Osteoporosis, characterized by loss of bone mass and deterioration of the architecture of bone tissue, resulting in increased bone fragility [1], has several subtypes, including gerontal osteoporosis and post-menopausal osteoporosis. Estrogen deficiency is considered as the major determinant of bone loss in postmenopausal women. Menopause results in elevated bone turnover, an imbalance between bone formation and bone resorption and net bone loss [2]. Hormone Replacement Therapy (HRT) was the effective treatment in preventing bone loss and reducing the incidence of skeletal fractures in postmenopausal women [3]. However, long-term HRT use has been proved to increase the risk of breast cancer, endometrial cancer, thromboembolic events and vaginal bleeding and it is a less desirable option for many women [4].

Corn Cervi Pantotrichum has been one of the most prized health tonics in traditional oriental medicine for over 2,000 years. Corn Cervi Pantotrichum, warm in nature, sweet and salty in flavour, was used as supplements for kidney, for strengthening bones, boosting the bone marrow and for nourishing the blood. As it has a unique natural model of rapid and complete bone regeneration, Corn Cervi Pantotrichum has received increasing attention because of its possible role in bone formation. The studies have found that Corn Cervi Pantotrichum growth factor could promote the viability and proliferation of primary human alveolar osteoblast cells in vitro [5]. Corn Cervi Pantotrichum extract may be a useful remedy for the treatment of bone-resorption diseases such as osteoporosis [6]. Zhou et al. have shown that a polypeptide from deer velvet accelerates fracture healing in laboratory mice by stimulating bone and cartilage formation [7].

But since now no studies have been carried out to evaluate whether Corn Cervi Pantotrichum has an antiosteoporosis activity either in a clinical or in an experimental study. The present research was conducted to investigate the effect of Corn Cervi Pantotrichum on postmenopausal osteoporosis in Ovariectomized (OVX) rats and explore the molecule 
mechanism of Corn Cervi Pantotrichum in treating postmenopausal osteoporosis.

\section{Materials and Methods}

\section{Drugs and reagents}

Corn Cervi Pantotrichum was purchased from Tianhuihonghe Co., LTD (China), smashed into powder and filtered by the 80 mesh screen, prepared into suspension solution with water. Climen tablets (Bayer Schering Pharma, Germany) which contain $2 \mathrm{mg}$ estradiol valerate and $1 \mathrm{mg}$ Cyproterone acetate was crushed, dissolved in water. Rat ALP Elisa kit, Rat osteocalcin Elisa kit, Rat BMP-2 Elisa kit, Rat Smad1 Elisa kit, Rat Smad5 Elisa kit, Rat Runx2 Elisa kit (All the Elisa kits were all bought from AMEKO, Shanghai Lianshuo Biological Technology Co., Ltd). Sheep polyclonal antibody anti-Osterix, rabbit polyclonal antibody anti-IgG.

\section{Animals and treatment}

40 female SPF Sprague-Dawley (SD) rats weighing 200-220 g were randomly divided into two groups, ten were for Sham operated, the other thirty were ovariectomized. All the animals were purchased from Liaoning Changsheng biotechnology co., LTD (China), and housed in a room at temperature of $21-25^{\circ} \mathrm{C}$, relative humidity of $50 \%-60 \%$ and a $12 \mathrm{~h}$ light $/ 12 \mathrm{~h}$ dark cycle. (All experimental designs and procedures had received approval from the Animal Ethics Committee of Liaoning university of traditional Chinese medicine). Animals had free access to pellet food and tap water.

After $7 \mathrm{~d}$ of acclimation, the rats were ovariectomized or Sham operated. The rats were anesthetized with $10 \%$ chloral hydrate solution (0.35 ml. $\mathrm{kg}^{-1}$, i.p.), the ovaries were removed bilaterally. Sham-operation was performed in the same manner but only exposing the ovaries. They were administrated with prophylactic penicillin (4000 IU kg-1, i.p.) for $4 \mathrm{~d}$. A week later, all the ovariectomized rats were randomly divided into three groups, each group has ten rats. Sham and Ovariectomized control (OVX) received the equivalence of distilled water through gastric tube. The treatment groups were given Corn Cervi Pantotrichum at the dose of 0.4 g. $\mathrm{kg}^{-1}$ body weight, Climen at $0.2 \mathrm{mg} \cdot \mathrm{kg}^{-1}$ daily for $12 \mathrm{w}$ via oral gavages. Climen group acted as the positive control group. Body weights of all animals were measured weekly.

At the end of the $12 \mathrm{w}$ trial, all the rats were deprived of food for one night. On the next day, the animals were anesthetized with $10 \%$ chloral hydrate solution $\left(0.35 \mathrm{ml} . \mathrm{kg}^{-1}\right.$, i.p. $)$, and blood were taken from abdominal aorta. The blood samples were centrifuged at $3000 \mathrm{rpm}$ (revolutions per minute) for 10 min to extract the serum and preserved at $-70^{\circ} \mathrm{C}$ for baseline bone biomarker measurements. After the collecting of blood, some selected organs (liver, spleen, kidney, and uterus) were carefully removed, cleaned and weighed. The femurs were isolated and after the removal of muscle and tendons, then washed with sterile normal saline. The right one was stored at $-70^{\circ} \mathrm{C}$ for bone mineral density detection. The left caput femoris was cut into pieces, half was put into $1 \mathrm{~mL}$ trizol for further RNA experiment, and half was stored at $-70^{\circ} \mathrm{C}$ for further protein experiment. The left femur was fixed in $10 \%$ formalin for histopathological evaluation. The tailbones were stored at $-70^{\circ} \mathrm{C}$ for ELISA.

\section{Bone mineral density}

Bone mineral density of the right femur was measured using dual-energy X-ray absorptiometry (Norland, USA) with the Small Subject Scout Scan. BMD was automatically calculated.

\section{Serum and femur biochemical analysis}

The serum was used for determining the activities of ALP, TRAP, E2, OT, BMP-2. The distal femur (the quarter from the aspect of the knee of the femur) were smashed and homogenized in PBS containing $0.05 \mathrm{mg} \cdot \mathrm{ml}^{-1}$ trasylol. The homogenate was centrifuged at $3,000 \mathrm{rhm}$ for $10 \mathrm{~min}$. After centrifugation, the bone extracts (supernatant fractions) were used for the activities of ALP, OT, BMP-2, Smad1, Smad5 and Runx2.All the activities were assayed with commercial kits and prepared using established protocols. The absorbance was read at $450 \mathrm{~nm}$ by multifunctional microplate reader (TECAN Infinite M200, Austria).

Table 1. The PCR primer sequences for rats.

\begin{tabular}{lll}
\hline Gene & \multicolumn{2}{l}{ Primer sequence } \\
\hline BMP2 & $\mathrm{F}$ & 5'-CTGCGGTCTCCTAAAGGTCG-3' \\
\cline { 2 - 3 } & $\mathrm{R}$ & 5'-ACTCAAACTCGCTGAGGACG-3' \\
\hline \multirow{2}{*}{ Smad1 } & $\mathrm{F}$ & 5'-GCAGTTGCTTACGAGGAACC-3' \\
\cline { 2 - 3 } & $\mathrm{R}$ & 5'-GGTGGACTCCTTTCCCGATG-3' \\
\cline { 2 - 3 } Smad5 & $\mathrm{F}$ & 5'-AGCAGAGATGTTCAGCCTGT-3' \\
\cline { 2 - 3 } & $\mathrm{R}$ & 5'-GCCTGGTGTTCTCGATGGTT-3' \\
\hline Runx2 & $\mathrm{F}$ & 5'-GCCTTCAAGGTTGTAGCCCT-3' \\
\cline { 2 - 3 } & $\mathrm{R}$ & 5'-TGAAACTCTTGCCTCGTCCG-3' \\
\hline B-actin & $\mathrm{F}$ & 5'-CGCGAGTACAACCTTCTTGC-3' \\
\hline
\end{tabular}

\section{Quantitative real-time PCR}

Total RNA was extracted from head of left femur using Trizol reagent (Invitrogen, Carlsbad, CA, USA). Real-time quantitative PCR analysis was performed on Stratagene Mx3000p (Agilent, German) by Brilliant III Ultra-Fast SYBR ${ }^{\circledR}$ Green QPCR Master Mix (Agilent Technologies, USA). The reactions were assembled following the manufacturer's recommendation. Briefly, $25 \mu \mathrm{l}$ of reaction mixture contain $1 \mathrm{X}$ buffer (iQ SYBR Green Supermix, Bio-Rad), $200 \mathrm{nM}$ forward and reverse primers, and the cDNA template from the sample. The PCR conditions are $3 \mathrm{~min}$ at $95^{\circ} \mathrm{C}$, followed by 40 cycles of $10 \mathrm{~s}$ at $95^{\circ} \mathrm{C}, 30 \mathrm{~s}$ at annealing temperature, and $30 \mathrm{~s}$ at $72^{\circ} \mathrm{C}$. The specificity of PCR was verified by measuring the melting curve of the PCR product at the end of reaction. Fluorescent data are specified for collection during primer 
extension. The relative cDNA ratio was calculated using the value of threshold cycles [8]. The PCR primer sequences for mouse are shown in Table 1.

\section{Western blot}

The total protein of the femur was extracted and the protein concentration was determined by lowry. The sample amount was $30 \mu \mathrm{g}$. After SDS-PAGE gel electrophoresis, the membranes were blocked for $2 \mathrm{~h}$ at room temperature with a blocking solution ( $5 \%$ non-fat milk in Tris buffered saline with Tween 20 (TBST) and incubated overnight at $4{ }^{\circ} \mathrm{C}$ with sheep polyclonal antibody anti-Osterix (1:3000), then added the secondary antibodies (1:5000, Beyotime Technology Inc.) for 2 $\mathrm{h}$ at room temperature. Finally, the Immunoreactive proteins were visualized by enzyme show method using the automatic digital gel imaging system. The electrophoretic bands were analysed with Scion Image software. The results of the graphs were expressed by target gray-scale value of straps/ $\beta$-actin gray-scale value of straps.

\section{Histopathological evaluation}

The femur was fixed in $10 \%$ formalin for $24 \mathrm{~h}$, decalcified in 20\% Ethylene Diamine Tetra Acetic Acid (EDTA) for $7 \mathrm{~d}$, and embedded into paraffin. The block was then cut into slices along the sagittal plane passing through the lengthways axis of the femur. The sections were stained with Hematoxylin and Eosin (HE), and examined for morphology under a light microscope [9].

\section{Statistical methods}

All of the data were expressed as mean values \pm Standard deviations. Statistical analysis was performed with one-way Analysis of Variance (ANOVA) using SPSS 16.0 software. The arithmetic means, Standard Deviations (SD) and $99 \%$ confidence intervals were calculated for each experimental group.

\section{Results}

\section{Bone mineral density}

The effects of Corn Cervi Pantotrichum on the BMD of the femur were presented in Figure 1. The BMD of femur was significantly lower in OVX group than in Sham group at $12 \mathrm{w}$ after the operation. The BMD of the femurs in the groups treated both with Corn Cervi Pantotrichum and Climen increased significantly compared with that in OVX group. There was no significant difference between the groups treated both with Corn Cervi Pantotrichum and Climen.

A

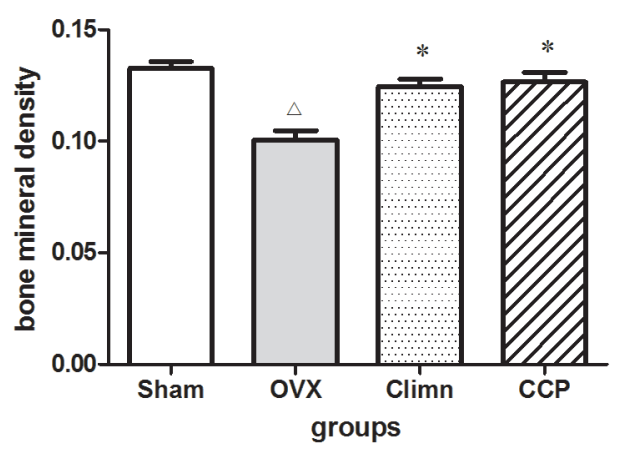

Figure 1. Effect of treatment of Corn Cervi Pantotrichum on BMD of femur for 12 .

\section{Biochemical markers}

The effect of Corn Cervi Pantotrichum on biochemical parameters both in serum and in femur were presented in Table 2. OVX rats showed significant lower levels of serum ALP, OT, BMP-2 and E2 compared with Sham rats, but has a higher level of TRAP than the sham rats. Administration of Corn Cervi Pantotrichum had remarkable influence on serum biochemical markers. Compared to the OVX group, the levels of ALP, OT, BMP-2 and E2 were higher in both the OVX + Corn Cervi Pantotrichum groups and the OVX+Climen. The levels of ALP, OT, and BMP-2 were much higher in OVX + Corn Cervi Pantotrichum groups than in the OVX+Climen $(\mathrm{P}<0.01)$, but the level of TRAP and E2 was significantly lower $(\mathrm{P}<0.01)$.

The femur levels of ALP, OT, BMP-2, Smad1, Smad5, Runx2 were significantly lower in the OVX group than in the Sham group $(\mathrm{P}<0.01)$. After given Corn Cervi Pantotrichum, all the biochemical parameters in femur were significantly increased $(\mathrm{P}<0.01)$.

Table 2. Effect of treatment of CCP on biochemical parameters in OVX rats for $12 w$ (n=10/group).

\begin{tabular}{|c|c|c|c|c|c|}
\hline & & Sham & ovx & OVX+Climen & $O V X+C C P$ \\
\hline \multirow[t]{5}{*}{ Serum } & ALP (U/L) & $227.18 \pm 7.20$ & $53.45 \pm 4.73$ & $124.02 \pm 9.53^{* *}$ & $178.03 \pm 9.54^{* *}$ \\
\hline & TRAP (pg/ml) & $63.78 \pm 11.05$ & $401.27 \pm 15.99$ & $199.29 \pm 12.54^{* *}$ & $126.85 \pm 14.12^{* \star}$ \\
\hline & От $(\mu \mathrm{g} / \mathrm{L})$ & $348.34 \pm 12.27$ & $86.76 \pm 4.01$ & $202.94 \pm 32.41^{* *}$ & $240.59 \pm 18.57^{* *}$ \\
\hline & BMP-2 ( $\mu \mathrm{g} / \mathrm{L})$ & $20.39 \pm 0.89$ & $5.55 \pm 0.54$ & $11.85 \pm 0.76^{* *}$ & $16.23 \pm 0.91^{* *}$ \\
\hline & $\mathrm{E} 2(\mathrm{Ng} / \mathrm{L})$ & $7.79 \pm 0.53$ & $1.36 \pm 0.05$ & $11.16 \pm 1.37^{* *}$ & $5.01 \pm 0.31^{* *}$ \\
\hline
\end{tabular}


Preventive and therapeutic effect of Corn Cervi Pantotrichum on bone tissue in ovariectomized rats through activation of BMP-2/Smads/Runx2 signal transduction pathway

\begin{tabular}{llllll}
\hline Bone tissure & BALP $(\mathrm{U} / \mathrm{L})$ & $4971.04 \pm 215.19$ & $753.28 \pm 82.52$ & $2775.66 \pm 181.17^{* *}$ & $4225.25 \pm 219.94^{* *}$ \\
\cline { 2 - 5 } OT $(\mu \mathrm{g} / \mathrm{L})$ & $583.27 \pm 49.12$ & $92.94 \pm 8.98$ & $303.95 \pm 15.85^{* *}$ & $438.57 \pm 20.53^{* *}$ \\
\hline BMP-2 $(\mu \mathrm{g} / \mathrm{L})$ & $37.29 \pm 1.29$ & $4.79 \pm 0.52$ & $20.95 \pm 3.08^{* *}$ & $25.13 \pm 2.12^{* *}$ \\
\hline Smad1 $(\mathrm{pg} / \mathrm{L})$ & $164.88 \pm 12.36$ & $60.76 \pm 6.68$ & $180.07 \pm 17.51^{* *}$ & $202.07 \pm 17.20^{* *}$ \\
\hline Smad5 $(\mathrm{pg} / \mathrm{L})$ & $53.7 \pm 5.35$ & $4.88 \pm 1.91$ & $24.94 \pm 6.27^{* *}$ & $34.07 \pm 2.15^{* *}$ \\
\hline Runx2 $(\mu \mathrm{g} / \mathrm{L})$ & $13.95 \pm 1.16$ & $2.03 \pm 0.03$ & $11.02 \pm 2.11^{* *}$ & $9.86 \pm 1.08^{* *}$ \\
\hline
\end{tabular}

Values have been indicated as mean \pm standard deviation, ${ }^{*} \mathrm{P}<0.05$ versus $\mathrm{OVX} ;{ }^{* *} \mathrm{P}<0.01$ vs. OVX; $\mathrm{P}<0.01$ vs. Sham

\section{Quantitative real time PCR}

BMP-2/Smads/Runx2 signal transduction pathway is important for osteoblast differtiation. Figure 2 represents the expression level of BMP-2, Smad1, Smad5, Runx2 mRNA in different groups rats. A marked decline in the expression level of BMP-2, Smad1, Smad5, Runx2 mRNA was observed in the OVX rats when compared to the sham group. Given Corn Cervi Pantotrichum for $12 \mathrm{w}$ increased the BMP-2, Smad1, Smad5, Runx2 mRNA expression level in OVX+Corn Cervi Pantotrichum group compared to that of OVX group. The Smad1, Smad5 mRNA was significantly higher than the positive group $(\mathrm{OVX}+\mathrm{Climen})$. These results showed that Corn Cervi Pantotrichum may upregulates BMP-2/Smad1, 5/Runx2 expression in OVX rats. This might be one of mechanism of Corn Cervi Pantotrichum promoting bone formation and repairing bone injury.
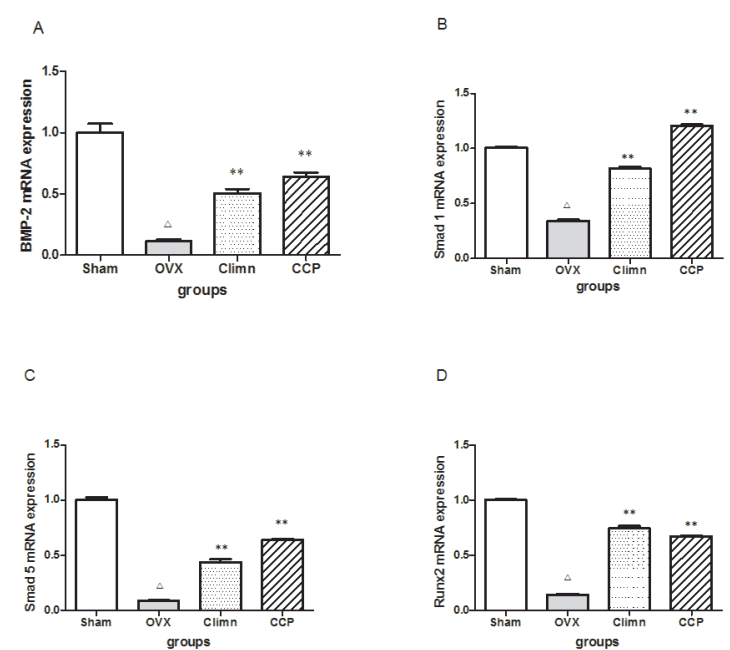

Figure 2. The results of quantitative real time PCR in different groups.

\section{Western blot}

BMP-2/Smads/Runx2 signal transduction pathway is important for osteoblast differentiation. Figure 3 and Table 3 represents the results of BMP-2, Smad1, Smad5, Runx2 in different groups rats. A marked decline of BMP-2, Smad1, Smad5, Runx2 mRNA was observed in the OVX rats when compared to the sham group. Given Corn Cervi Pantotrichum for $12 \mathrm{w}$ increased the BMP-2, Smad1, Smad5, Runx2 mRNA expression level in OVX+Corn Cervi Pantotrichum group compared to that of OVX group. The Smad1, Smad5 mRNA was significantly higher than the positive group (OVX + Climen). These results are found to be in line with the PCR experimental results.

Table 3. The results of western blot in different groups ( $n=8 /$ group).

\begin{tabular}{|c|c|c|c|c|c|c|c|c|}
\hline & & Sham & & ovx & & ovX+Clime & & $\mathrm{OVX}+\mathrm{CCP}$ \\
\hline \multirow[t]{4}{*}{$\begin{array}{l}\text { Bone } \\
\text { tissure }\end{array}$} & BMP-2 & $\begin{array}{l}0.7640 \\
0.1397\end{array}$ & \pm & $\begin{array}{l}0.5930 \\
0.0881\end{array}$ & \pm & $\begin{array}{l}0.6410 \\
0.1062\end{array}$ & \pm & $\begin{array}{l}0.7048 \\
0.0836^{*}\end{array} \quad \pm$ \\
\hline & Smad1 & $\begin{array}{l}0.9235 \\
0.2188\end{array}$ & \pm & $\begin{array}{l}0.4899 \\
0.0980\end{array}$ & \pm & $\begin{array}{l}0.7545 \\
0.1337^{* *}\end{array}$ & \pm & $\begin{array}{l}0.7911 \\
0.1831^{\text {** }}\end{array} \quad \pm$ \\
\hline & Smad5 & $\begin{array}{l}0.7239 \\
0.1228\end{array}$ & \pm & $\begin{array}{l}0.2987 \\
0.0753\end{array}$ & \pm & $\begin{array}{l}0.4156 \\
0.0889^{* *}\end{array}$ & \pm & $\begin{array}{l}0.5041 \\
0.1091^{\text {** }}\end{array}$ \\
\hline & Runx2 & $\begin{array}{l}0.8857 \\
0.1060\end{array}$ & \pm & $\begin{array}{l}0.4907 \\
0.0982\end{array}$ & \pm & $\begin{array}{l}0.6605 \\
0.0717^{\star *}\end{array}$ & \pm & $\begin{array}{l}0.6295 \\
0.1291^{*}\end{array} \quad \pm$ \\
\hline
\end{tabular}

Values have been indicated as mean \pm standard deviation, ${ }^{*} \mathrm{P}<0.05$ vs. OVX; ${ }^{* *} \mathrm{P}<0.01$ vs. OVX; $\mathrm{P}<0.01$ vs. Sham

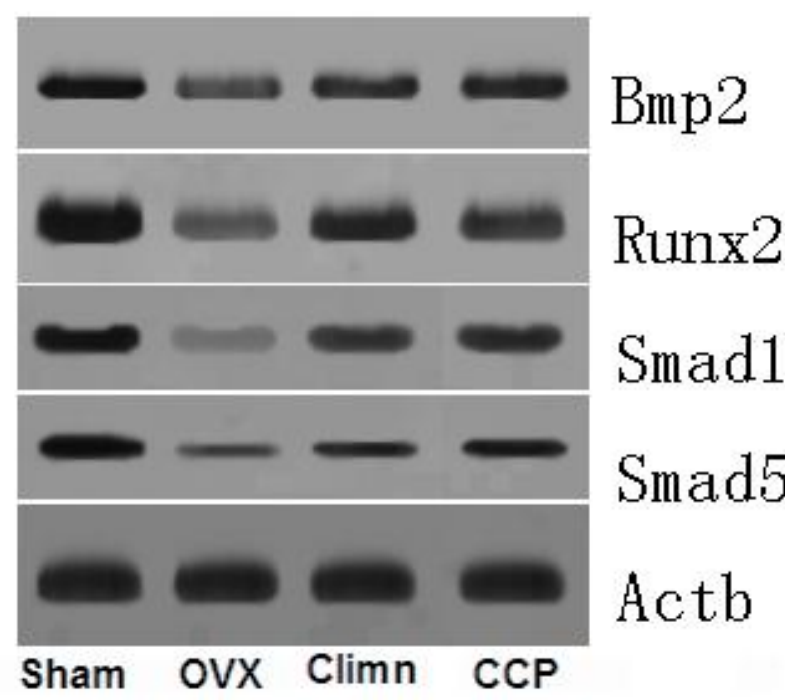

Figure 3. Morphology of the femur head in different groups.

\section{Femur histological analysis}

The Femur histological analysis results were showed in Figure 4 under the light microscope, the histology of the lumbar 
vertebra of Sham rats revealed normal size, shape, density and architecture of trabecular bone (A); OVX group sections exhibited sparse, disrupted, spacing-enlarged and areadiminished trabecular bone (B). After given Corn Cervi Pantotrichum and Climen for $12 \mathrm{w}$, there was significant restorative progress in the two groups. The result indicates that the curative effect of Corn Cervi Pantotrichum was superior to Climen (C and D).
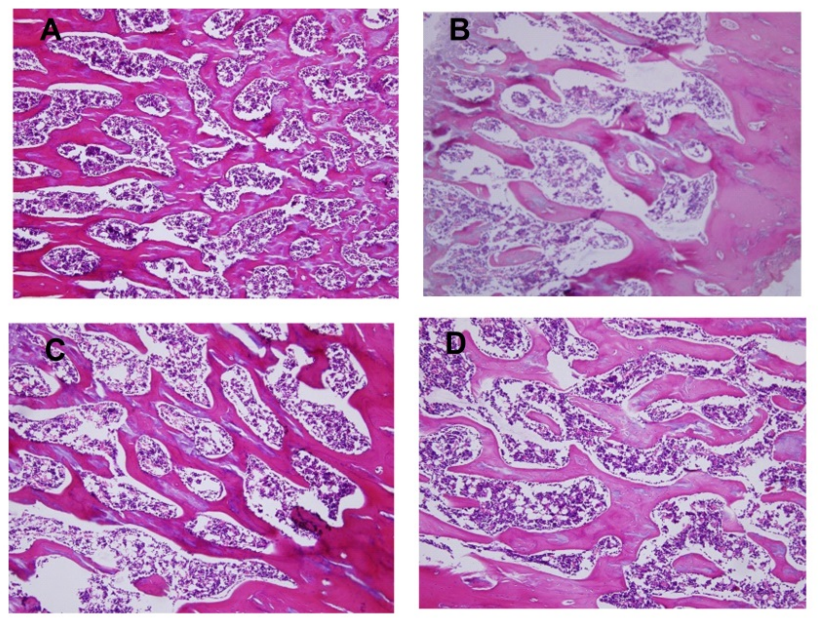

Figure 4. The results of Western blot in different groups.

\section{Discussion}

This study is to evaluate the effect of Corn Cervi Pantotrichum on osteoporosis induced by ovariectomy. It is known that estrogen deficiency is an important risk factor in the pathogenesis of osteoporosis. Ovariectomy in the rats results in an increase in bone turnover rate and significant loss of cancellous bone such as the proximal femur, vertebral bodies and the metaphysis of long bones [10]. In our study, ovariectomy rats for $12 \mathrm{w}$ induced a decrease in femur BMD. ALP, OT and BMP-2 are all bone formation markers. ALP is known to be associated with bone metabolism and differentiation of osteoblasts. TRAP has been used as a marker enzyme of bone-resorbing osteoclasts. This enzyme is secreted into the circulation by osteoclasts, and it has been suggested that serum TRAP could be a useful marker of bone resorption. The serum level of ALP, OT, BMP-2 were lower in the OVX group than in the Sham group, but the TRAP level in the OVX group was significantly increased. This indicated that trabecular bone loss had occurred. After given Corn Cervi Pantotrichum for $12 \mathrm{w}$, there was a marked increase in BMD. The level of ALP, OT, BMP-2 were increased and the TRAP was reduced. These results indicate that Corn Cervi Pantotrichum play a positive role in the treatment and prevention of osteoporosis in OVX rats, administration of Corn Cervi Pantotrichum can inhibit bone absorption, and improve bone remodeling.

Orlaith et al. detected that a continued increase in bone resorption and relative reduction in bone formation, leading to deterioration in bone microarchitecture according to estrogen deficiency [11]. Estrogen deficiency during menopause causes rapid bone loss, especially in the early years after menopause. Previous studies have found that Corn Cervi Pantotrichum contained six nature sex hormone such as estriol, 17 $\beta$-estradiol, estrone, corticosterone, testosterone, progesterone and so on. In our research we have found that $17 \beta$-estradiol was lose much in the OVX rats. Corn Cervi Pantotrichum contains hormone which can help to complement the oestrogen level and the serum level of E2 in OVX+Corn Cervi Pantotrichum group was significantly higher than in the OVX group. The femur histological analysis showed that Corn Cervi Pantotrichum could prevent damages to bone tissue.

It is known that BMP signaling is transduced by the SMAD family, including Smad1, Smad4 and Smad5 [12]. They form a complex, move into the nucleus, and activate target genes [13]. Bone Morphogenetic Proteins (BMPs), with more than 20 members, belong to the TGF- $\beta$ superfamily and were originally identified by their unique ability to induce ectopic cartilage and bone formation in vivo [14]. BMPs play important roles in bone formation and bone cell differentiation by stimulating alkaline phosphatase activity and synthesis of proteoglycan, collagen, fibronectin, and osteocalcin [15]. Among BMP family members, BMP-2 has been extensively studied and demonstrated to play a crucial role in inducing osteoblast differentiation and bone formation during embryonic skeletal development and postnatal bone remodeling [16]. After specific receptors binding, BMP-related effects are mediated by different signaling pathways including the Ras/MAPK system, different Smad proteins, $\mathrm{Ca}^{2+}$, cAMP, the Runx/Cbfa1 pathway, and the Wnt/ $\beta$-catenin system $[17,18]$. The BMP-2/ Smads/Runx2 signal transduction pathway is important for osteoblast differentiation.

Upon activation of the receptors by the cytokine, the type I receptor phosphorylates specific intracellular proteins named Smads. Smad1 and Smad5 are often referred to generically as mediators of the BMP signaling pathway. It has been reported that Smad1 is a mediator of the intracellular signaling of BMP-2/4 for inducing ventral mesoderm in Xenopus [19-22]. Smad5, also termed dwarfin-C, is thought to act downstream of BMP signaling pathways, because of the high homology with Smad1, termed dwarfin-A (95\% homologous). Smad5 induces ventral mesoderm in Xenopus embryo, suggesting that Smad5 acts as a signal mediator of BMP-2/4 as well. BMP2 exhibits this osteogenic action by activating Smad1/5/8 signaling and regulating the transcription of osteogenic genes [23]. Runx2 is transcriptionally regulated by various molecules, including fibroblast growth factors, TGF-b and BMP [24]. BMP-2 is the most potent osteogenic agents, which strongly promotes the differentiation of pluripotent mesenchymal cells into osteoblastic cells and is also involved in chondrogenic differentiation [25,26]. Previous studies using pluripotent mesenchymal cell lines have shown that Runx 2 mRNA was induced by BMP-2, and that Runx2 activity was reduced by blocking BMP-2 [27-29]. In our study, we used Elisa to track the expression of protein and used quantitative real-time PCR to track the expression of mRNA in several osteoblast phenotypic markers in the femur. We confirmed that Corn Cervi Pantotrichum has a positive effect on post-menopausal 
osteoporosis by up-regulating BMP-2/Smad1,5/Runx2. The experiment results showed that a marked decline in both the protein expression level and the mRNA expression of BMP-2, Smad1, Smad5, Runx2 mRNA was observed in the OVX rats when compared to sham group. Given Corn Cervi Pantotrichum for $12 \mathrm{w}$ could increase the BMP-2, Smad1, Smad5, Runx2 protein and mRNA expression level in OVX +Corn Cervi Pantotrichum group compared to that of OVX group. The Smad1, Smad5 mRNA was significantly higher than the positive group $(\mathrm{OVX}+\mathrm{Climen})$. These results showed that Corn Cervi Pantotrichum may upregulates BMP-2/Smad1, 5/Runx2 expression in OVX rats.

\section{Conclusion}

Corn Cervi Pantotrichum has potential as a safer alternative for prevention of post-menopausal osteoporosis. It may be taken as supplements by post-menopausal women who want to protect themselves against osteoporosis but are afraid of the estrogens' side-effects and Corn Cervi Pantotrichum could up-regulate BMP-2/Smad1, 5/Runx2 expression. This might be one of mechanism of Corn Cervi Pantotrichum promoting bone formation and repairing bone injury.

\section{Acknowledgements}

This work was supported by the National Natural Science Foundation of China (No.81473314), Liaoning province Natural Science Foundation (No.20170540606).

\section{References}

1. Cauley JA, Thompson DE, Ensrud KC, Scott JC, Black D. Risk of mortality following clinical fractures. Osteoporos Int 2000; 11: 556-561.

2. Hagino H, Kishimoto H, Ohishi H, Horii S, Nakamura T. Efficacy, tolerability and safety of once-monthly administration of $75 \mathrm{mg}$ risedronate in Japanese patients with involutional osteoporosis: a comparison with a 2.5mg once-daily dosage regimen. Bone 2014; 59: 44-52.

3. Turner RT, Riggs BL, Spelsberg TC. Skeletal effects of estrogen. Endocrine Rev 1994; 15: 275-300.

4. Gartlehner G, Patel SV, Feltner C, Weber RP, Long R, Mullican K, Boland E, Lux L, Viswanathan M. Hormone therapy for the primary prevention of chronic conditions in postmenopausal women: evidence report and systematic review for the US preventive services task force. JAMA 2017; 318: 2234-2249.

5. Laky M, Qu Z, Ho E. The effect of deer antler growth factor on the viability and proliferation of primary human alveolar osteoblast cells in vitro. Int J Stomatol Occlus Med 2009; 2: 175-178.

6. Li YK, Tae HK, Han B. Chloroform extract of deer antler inhibits osteoclast differentiation and bone resorption. J Ethnopharmacol 2007; 113: 191-198.

7. Zhou QL, Guo YJ, Wang LJ. Corn Cervi Pantotrichum polypeptides promoted proliferation of chondrocytes and osteoblast precursors and fracture healing. Acta Pharmacologica Sinica 1999; 20: 279-282.

8. Ye J, Coulouris G, Zaretskaya I. Primer-BLAST: a tool to design target-specific primers for polymerase chain reaction. BMC Bioinform 2012; 13: 134.

9. Pazdzior-Czapula K, Rotkiewicz T, Otrocka-Domagała I, Gesek M, Smiech A. Morphology and immunophenotype of canine cutaneous histiocytic tumours with particular emphasis on diagnostic application. Vet Res Commun 2015; 39: 7-17.

10. Omi N, Ezawa I. The effect of ovariectomy on bone metabolism in rats. Bone 1995; 17: 163-168.

11. Orlaith B, Julia SK, Clive Lee T. Temporal changes in bone composition, architecture, and strength following estrogen deficiency in osteoporosis. Calcified Tissue Int 2012; 6: 440-449.

12. Zhang $\mathrm{H}, \mathrm{Du}$ L, Zhong Y, Flanders KC, Roberts JD. Transforming growth factor- $\beta$ stimulates Smad1/5 signaling in pulmonary artery smooth muscle cells and fibroblasts of the newborn mouse through ALK1.Am J Physiol Lung Cell Mol Physiol 2017; 313: 615-627.

13. Wu J, Ru NY, Zhang Y, Li Y, Wei D, Ren Z, Huang XF, Chen ZN, Bian H. HAb18G/CD147 promotes epithelialmesenchymal transition through TGF- $\beta$ signaling and is transcriptionally regulated by Slug. Oncogene 2011; 30: 4410-4427.

14. Jani P, Liu C, Zhang H, Younes K, Benson MD, Qin C. The role of bone morphogenetic proteins 2 and 4 in mouse dentinogenesis. Arch Oral Biol 2018; 90: 33-39.

15. Sakou TL, Onishi T, Yamamoto T, Nagamine T, Sampath TK, Ten Dijke P. Localization of Smads, the TGF-beta family intracellular signaling components during endochondral ossification. J Bone Miner Res 1999; 14: 1145-1152.

16. Wozney JM, Rosen V, Celeste AJ, Mitsock LM, Whitters MJ, Kriz RW, Hewick RM, Wang EA. Novel regulators of bone formation: molecular clones and activities. Science 1988; 242: 1528-1534.

17. Sapkota G, Alarcon C, Spagnoli FM, Brivanlou AH, Massague J. Balancing BMP signaling through integrated inputs into the Smad1 linker. Mol Cell 2007; 25: 441-454.

18. Lian JB, Stein GS, Javed A. Networks and hubs for the transcriptional control of osteoblastogenesis. Rev Endocrine Metabol Disord 2006; 7: 1-16.

19. Lian JB, Stein GS, Javed A, van Wijnen AJ, Stein JL, Montecino M, Hassan MQ, Gaur T, Lengner CJ, Young DW. MADR2 maps to 18Q21 and encodes a TGF-BETAregulated MAD-related protein that is functionally mutated in colorectal carcinoma. Rev Endocr Metab Disord 2006; 7: 1-16.

20. Liu F, Hata A, Baker JC, Doody J, Cárcamo J, Harland RM, Massague J. A human Mad protein acting as a BMPregulated transcriptional activator. Int J Sci 1996; 381: 620-623.

21. Kim RH, Wang D, Tsang M, Martin J, Huff C, de Caestecker MP, Parks WT, Meng X, Lechleider RJ, Wang 
T, Roberts AB. A novel Smad nuclear interacting protein, SNIP1, suppresses p300-dependent TGF-beta signal transduction. Genes Dev 2000; 14: 1605-1616.

22. Piesanen JVI, Nikkari ST, Kunnas TA. Genetic variation in bone morphogenetic proteins family members (BMPs 2 and 4) and hypertension risk in middle-aged men: The TAMRISK study. Medicine (Baltimore) 2017; 96: 9362.

23. Jin EJ, Lee SY, Choi YA, Jung JC, Bang OS, Kang SS. Smad5 induces ventral fates in Xenopus embryo. Develop Biol 1997; 184: 402-405.

24. Komori T. Roles of Runx2 in skeletal development. Adv Exp Med Biol 2017; 962: 83-93.

25. Cheng H, Jiang W, Phillips FM, Haydon RC, Peng Y, Zhou L, Luu HH, An N, Breyer B, Vanichakarn P, Szatkowski JP, Park JY, He TC. Osteogenic activity of the fourteen types of human bone morphogenetic proteins (BMPs). J Bone Joint Surg Am 2003; 85: 1544-1552.

26. Jin EJ, Lee SY, Choi YA, Jung JC, Bang OS, Kang SS. BMP-2 enhanced chondrogenesis involves p38 MAPKmediated down-regulation of Wnt-7a pathway. Mol Cells 2006; 22: 353-359.

27. Lee KS, Kim HJ, Li QL, Chi XZ, Ueta C, Komori T, Wozney JM, Kim EG, Choi JY, Ryoo HM, Bae SC. Runx2 is a common target of transforming growth factor beta 1 and bone morphogenetic protein 2, and cooperation between Runx2 and Smad5 induces osteoblast-specific gene expression in the pluripotent mesenchymal precursor cell line C2C12. Mol Cell Biol 2000; 20: 8783-8792.

28. Yang B, Lin X, Yang C, Tan J, Li W, Kuang H. Sambucus Williamsii Hance promotes MC3T3-E1 cells proliferation and differentiation via BMP-2/Smad/p38/JNK/Runx2 signaling pathway. Phytother Res 2015; 29: 1692-1699.

29. Li L, Sapkota M, Gao M, Choi H, Soh Y. Macrolactin F inhibits RANKL-mediated osteoclastogenesis by suppressing Akt, MAPK and NFATc1 pathways and promotes osteoblastogenesis through a BMP-2/smad/Akt/ Runx2 signaling pathway. Eur J Pharmacol 2017; 815: 202-209.

\section{*Correspondence to}

Hongxin Zheng

Liaoning University of Traditional Chinese Medicine

Liaoning

PR China

\section{Feng Li}

Liaoning University of Traditional Chinese Medicine

Liaoning

PR China 